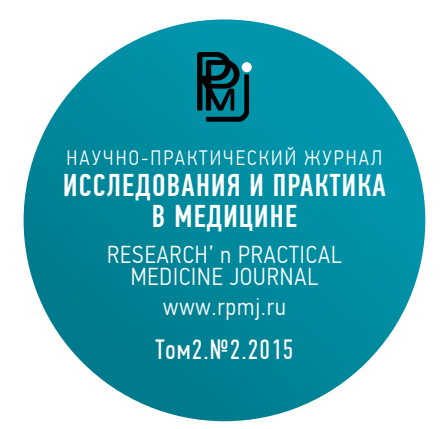

Ключевые слова:

врач, пациент, психология врача, коммуникации, здравоохранение, медицинская организация, профессиональное образование профессионализация.

Keywords:

health care, medical staff, personnel, HR policies, HR processes, staffing, education, management

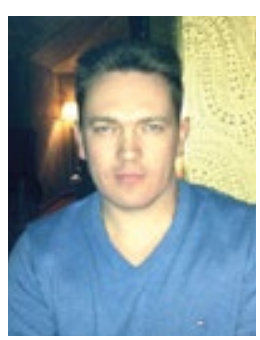

Для корреспонденции: Самсонов Юрий Владимирович к. М. Н., ведущий научный сотрудник РЦИТЭО, МНИОИ им. П.А. Герцена - филиала ФГБУ «НМИРЦ» Минздрава России

Адрес: 125284 , Российская Федерация,

Москва, 2-ой Боткинский проезд. д. 3.

E-mail: samsonovu@list.ru

Статья поступила 04.05.2015

принята к печати 11.06.2015

For correspondence:

Samsonov Yury Vladimirovich -

PhD, leading researcher of RCITEO, P. Hertsen MOR

Address: 2-y Botkinskiy proezd, d.3,

Moskva, 125284, Russia

E-mail: samsonovu@listru

The article was received 04.05.2015

accepted for publication 11.06 .2015

\section{ПСИХОЛОГИЧЕСКИЕ АСПЕКТЫ ЛИЧНОСТИ ВРАЧА В ПРОЦЕССЕ ЕГО ПРОФЕССИОНАЛИЗАЦИИ}

\author{
Каприн А.Д. ${ }^{1}$, Костин А.А. ${ }^{1}$, Пономаренко Б.Т. ${ }^{2}$, Гриднев 0.В. ${ }^{3}$, Самсонов Ю.В ${ }^{4}$
}

1 ФГБУ «НМИРЦ» Минздрава России

249036, Российская Федерация, Калужская область, г. Обнинск, ул. Королёва, д. 4

${ }^{2}$ РАНХ и ГС при Президенте Российской Федерации

119606, Российская Федерация, Москва, Проспект Вернадского, 84

${ }^{3}$ ГБУЗ города Москвы «Городская клиническая больница № 50»

Департамента здравоохранения города Москвы

127206, Российская Федерация, Москва, ул. Вучетича, д. 21

4 МНИОИ им. П.А. Герцена - филиал ФГБУ «НМИРЦ» Минздрава России

125284, Российская Федерация, г. Москва, 2-ой Боткинский проезд, дом 3

127473, Российская Федерация, Москва, ул. Делегатская, д.20, стр.1

\section{Резюме:}

В статье рассматриваются вопросы формирования психологических качеств лечащего врача в процессе его профессионализации. Проанализирована роль врача в российском обществе. Охарактеризована психология лечащего врача и специфика его деятельности. Выделены проблемные вопросы формирования психологии врача.

Ключевые слова: врач, пациент, психология врача, коммуникации, здравоохранение, медицинская организация, профессиональное образование, профессионализация.

\section{PSYCHOLOGICAL ASPECTS OF THE PERSONALITY OF THE DOCTOR IN THE PROCESS OF PROFESSIONALIZATION}

\author{
Kaprin A.D. ${ }^{1}$, Kostin A.A. ${ }^{1}$, Ponomarenko B.T. ${ }^{2}$, Gridnev O.V. ${ }^{3}$, Samsonov Y.V. ${ }^{4}$ \\ ${ }^{1}$ National Medical Research Radiological Centre of the Ministry of Health of the Russian Federation \\ 4. Ulitsa Korolyeva, Oblinsk, Kaluzskaya Oblast', 249036, Russia \\ ${ }^{2}$ Russian Presidental Academy of National Economy and Public Administration \\ 84, Prospect Vernadskogo, Moscow, 119606, Russia \\ ${ }^{3}$ Moscow SBMH «City clinical hospital No. 50» of the health Department of Moscow \\ 21. Ulitsa Vucheticha, Moscow, 127206, Russia \\ ${ }^{4}$ P. A. Hertsen Moscow Oncology Research Institute — branch of the National Medical Research Radiological \\ Centre of the Ministry of Health of the Russian Federation \\ 2-y Botkinskiy proezd, d.3, Moskva, 125284, Russia
}

\section{Abstract:}

The personnel potential of the Russian health care system has been analyzed. The main issues and trends in the development of our personnel, the dynamics of human processes in health care organizations have been revealed. The correlation of modernization processes with quantitative and qualitative indicators of their personnel has been determined. The role of the personnel policy of the industry in the development of HR processes in the health system has been characterized.

Профессия врача - одна из самых древних и наиболее почитаемых на земле профессий. В ней выражается свойственная человеку потребность оказывать помощь нуждающемуся. С развитием общества менялось и положение врача, возрастал его общественный престиж и авторитет, столь необходимый для осуществления профессиональной деятельности, изменялись требования к врачу и к здравоохранению в целом. Однако, вне зависимости от социально-общественных формаций, обязательным условием успешного врачевания было и остается соблюдение общепринятых морально-этических принципов во взаимоотношениях врача и больного.

И потому важно учитывать, кто избирает профессию врача и как он выполняет моральные обязанности по профессии, какими социо-психическими каче- 
ствами обладает. По образному выражению А. П. Чехова, «профессия врача сродни подвигу. Она требует самоотверженности, чистоты духа и чистоты помыслов». Роль врача в современном российском обществе трудно переоценить. Ведь врач - это человек, который использует свои знания и умения, руководствуясь высокими помыслами и гражданскими устремлениями для диагностики и лечению заболеваний, сохранения и укрепления здоровья пациентов. В связи с тем, что объектом деятельности врача является человек, требования к моральным, гражданским, интеллектуальным качествам специалиста всегда были выше нежели к другим категориям работников.

Как показывает лечебный, научный и управленческий опыт, в психологическом плане для практикующего врача важны три приоритета: предотвращение (профилактика), диагностика (распознание) и лечением (терапия) заболеваний. Труд врача весьма сложен. Известно, что успех и почтение обусловлены непрерывным совершенствованием его медицинских познаний, врачебным профессионализмом, налаживанием эффективных коммуникаций с пациентами. Сюда же относятся: непрерывное познание взаимосвязанных фундаментальных и специальных клинических дисциплин, освоение современных методов диагностики болезней, освоение лучшего медицинского опыта, непосредственное общение с пациентами, проникновение врача в суть их нужд и переживаний. Успешное лечение, даже при использовании достижений медицинской науки, в значительной степени обусловлены освоением искусства профессионального врачевания.

В концептуальном плане роль врача определена в законодательстве Российской Федерации устанавливающем, что «лечащий врач - это специалист, на которого возложены функции по организации и непосредственному оказанию пациенту медицинской помощи в период наблюдения за ним и его лечения», а «пациент - физическое лицо, которому оказывается медицинская помощь или которое обратилось за оказанием медицинской помощи независимо от наличия у него заболевания и от его состояния» [1]. Осознание врачом себя как специалиста в медицинской организации является психологическим условием профессионализации его личности.

При получении высокого звания врача выпускник медицинского вуза принимает на себя ряд клятвенных моральных обязательств, предопределяющих психологию его развития как личности и гражданина. Приоритет интересов пациента при оказании медицинской помощи - это, своего рода, главный жизненный императив и психологическая ориентация деятельности врача. Как следует из Клятвы врача [2], которая дается в торжественной обстановке при получении вузовского диплома, честное исполнение врачебного долга, посвящение своих знаний и умений предупреждению и лечению заболеваний, сохранению и укреплению здоровья человека, готовность всегда оказать медицинскую помощь и хранить врачебную тайну, внимательно и заботливо относиться к пациенту, соблюдать этические и моральные нормы, а также проявлять уважительное и гуманное отношение к пациентам считаются его непреложным жизненным кредом.
Как известно, врача характеризуют, прежде всего, профессиональный уровень, квалификация, развитый профессионализм. Однако неотъемлемым атрибутом личности наряду с квалификацией является психология врача. Ведь при наличии вариантов выбора врача пациент отдает предпочтение более вежливому и корректному специалисту, нежели грубому и равнодушному. Помимо высокой квалификации, психологически осмысленное отношение к пациентам - залог признания авторитета и успеха медицинской профессии.

В системе здравоохранения Российской Федерации трудятся 614,1 тыс. врачей, обладающих в большинстве своем глубокими знаниями, профессиональным опытом, развитым человеколюбием, чувственным отношение к пациентам. Медицинский персонал относится к дорогостоящим ресурсам, требующим больших затрат на подготовку квалифицированных специалистов. В отличие от большинства ресурсов, ценность которых со временем снижается, ценность кадровых ресурсов с накоплением профессионализма и опыта лишь увеличивается.

На протяжении нескольких десятилетий общей стратегической линией кадровой политики в здравоохранении являлось неуклонное наращивание численности медицинских кадров, а качественный уровень специалистов имел устойчивую тенденцию к снижению. Сейчас, при общем количестве врачей 614,1 тыс. человек на 10 тыс. населения приходится 44 врача. Это превышает показатель развитых стран, в т.ч. США, Германии, Франции. Уровень обеспеченности врачебными кадрами в целом по России за последние годы возрастал, а по субъектам Федерации отмечалась диспропорция этого роста более чем вдвое. Асимметрия показателей обеспеченности кадрами в субъектах Федерации, разнонаправленность имеющихся тенденций не дают возможности обеспечить равную доступность и качество медицинской помощи всех категорий населения.

Психологический анализ врачебной деятельности сопряжен с выделением системы отношений субъектного, объектного, субъектно-объектного типа и социальных отношений, опосредующих процесс взаимодействия врача и пациента [3]. Лечащий врач - основной элемент этой системы. Это он призван обеспечить целевую направленность и эффективность ее функционирования. Роль лечащего врача состоит, прежде всего, в том, что он организует своевременное и квалифицированное обследование и лечение пациента, предоставляя информацию о состоянии его здоровья, приглашает консультантов и организует консилиум. К тому же, рекомендации консультантов могут быть приняты преимущественно по согласованию с лечащим врачом. Именно лечащий врач несет ответственность за недобросовестное выполнение своих профессиональных обязанностей в соответствии с российским законодательством.

Роль врача в российском обществе обусловлена также его коммуникациями с пациентом в стремлении достичь результата диагностики и лечения. Это определяется обстоятельным и правдивым информированием пациента о выборе технологий профилактики и лечения, вероятных исходах лечения; единой методикой оценки врача по результатам профилактической и лечебной 
деятельности. Пациент должен почувствовать, что врача, к которому он пришел за помощью, интересуют не только вопросы диагностики, но и обратившийся к нему человек. А если вести речь о враче, то в процессе общения с пациентом он должен ощутить его переживания и эмоциональное состояние, показать свое сопереживание и стремление к соучастию в решении проблемы. И не столько исходя из словесных сообщений, сколько из характера его невербального поведения.

Профессиональное самосознание побуждает врачей к построению своего поведения соответственно задачам медицинской организации и его функциям, сознательному подчинению поступков этическим и профессиональным требованиям, надлежащему владению собой, личными чувствами, устремлениями, эмоциями и переживаниями. Именно от профессионального самосознания зависят формирование социо-психических состояний, оценка своих знаний и умений, осуществление задач профессионального самосовершенствования. Потребность в самооценке побуждает врача к осознанию себя как личности, активизирует процесс саморегуляции, самопознания и самосовершенствования.

Структура профессионального самосознания врача и его стремление к повышению качества медицинской деятельности требуют непрерывного профессионального развития, совершенствования управления этим многоплановым процессом. Исходя из Клятвы, данной выпускником медицинского вуза, врач должен «постоянно совершенствовать свое профессиональное мастерство, беречь и развивать благородные традиции медицины». Приоритет развития личности врача в процессе его профессионализации предопределяет успех и эффективность врачебной деятельности. Совершенствование психологии врачебного труда как системного явления требует непрерывной социализации и профессионализации. По своей глубинной сути профессионализация это основа развития личности врача, важная форма его личностной активности. Сам же процесс непрерывного профессионального развития врача должен быть всецело подчинен обеспечению соблюдения основных принципов охраны здоровья, установленных российским законодательством. Испытанной формой социализации врача выступают его профессиональная подготовка и последующее последипломное (непрерывное) обучение, формирование требуемых компетентностей и компетенций. К наиболее профессионально значимым психологическим качествам врача относятся: широкий диапазон знаний, коммуникативная компетентность, эмоциональная стабильность, способность к эмпатии, уверенность в своих действиях.

Известно, что деятельность врача проходит в условиях повышенных социо-психологических требований. В большинстве своем она связана с высоким умственным и психоэмоциональным напряжением. Специфика эмоционального реагирования на различные ситуации врачебной деятельности, как и факторы влияния на профессионально-личностное развитие врача, индивидуально-психологические особенности, присущие врачам различных специализаций - это вопросы, требующие специального изучения и реагирования. Поэтому, про- блемы психологии медицинского труда и личности врача относятся к весьма актуальным в теоретической и прикладной социальной психологии в целом и ее отрасли, относящейся к социологии и психологии медицины.

В контексте рассмотрения психологических особенностей социального и профессионального развития врача на первый план обычно выносится вопрос об ответственности за качество медицинской помощи населению. Высокий уровень качества профессионального исполнения врачом своих функций и задач определяется многими факторами. К наиболее существенным относятся: стандарты деятельности по медицинским специальностям, контроль за их выполнением со стороны профессиональных медицинских объединений, развитая система непрерывного последипломного образования, освоенная в медицинской организации корпоративная этика, страхование профессиональной ответственности.

Динамичным оснащением и освоением медицинскими организациями передовых технологий, широким внедрением современной техники и эффективных принципов управления обусловлена необходимость более полного учета личностных факторов врача, его психологических характеристик. Это достигается как в процессе профессиональной подготовки, так и на протяжении всего профессионального пути субъекта врачебной деятельности. Профессиональное становление врача как субъекта медицинского труда - это сложный процесс. Он включает в себя формирование совокупности профессиональных знаний, умений и навыков - с одной стороны, и профессионально значимых социо-психологических качеств - с другой.

Первая из названных составляющих реализуется в процессе последипломного непрерывного медицинского образования. Другая - путем выбора методологии психологического сопровождения личности врача на всех этапах его личностного самоопределения и профессионального развития, что остается слабо разработанным в теории и медицинской практике. Такого рода задача могла бы быть решена через разработку и реализацию программы психологического сопровождения процесса непрерывного профессионального медицинского образования на вузовском и послевузовском этапах, профессионального развития личности практикующего врача в условиях конкретной медицинской организации.

Сейчас в основу подготовки квалифицированных специалистов для медицинских организаций положены профессиональные стандарты. Целевое предназначение 27 принятых Минздравом России стандартов (набор компетенций специалиста) подчинено формированию на территории страны единых подходов к определению готовности специалиста к занятию соответствующей должности, обеспечению раскрытия содержания требований к квалификациям медицинских и фармацевтических работников [4].

Замечено, что одна из примечательных психологических особенностей деятельности врача заключается в уровне развития используемых коммуникативных и организаторских ресурсов. Например, в условиях проявления конфликтных ситуаций, которые порой возни- 
кают в медицинской организации, для деятельности врачей-терапевтов присущ выбор стратегий сотрудничества. В то же время, врачи анестезиолого-реаниматологического и хирургического направлений отдают предпочтение преимущественно авторитарным стратегиям разрешения межличностных конфликтов. Это можно рассматривать как субъектные качества, формирование которых детерминировано спецификой профессиональной деятельности в определенных видах врачебного труда.

В том, что в системе здравоохранения проявились позитивные тенденции качественного роста, огромная заслуга врачей медицинских организаций. В нынешнем году в медицинских организациях столичного здравоохранения осваиваются инновационные подходы, реализуется комплексная программа профилактической помощи населению, профессионального развития врачей [5].

Теоретико-методологическая и организационнопрактическая востребованность системного социо-

\section{Список литературы:}

1. Федеральный закон «Об основах охраны здоровья граждан в Российской Федерации от 21.11.2011 г. №323-Ф3. Пункт 15 ст.2.

2. Федеральный закон «Об основах охраны здоровья граждан в Российской Федерации от 21.11.2011 г. №323-Ф3. Пункт 15 ст.71.

3. Деркач А.А. Субъект: формы, механизмы и пути развития. -Казань: ЦИТ, 2011.

4. Модернизация здравоохранения: новая ситуация и новые задачи. -М.:Дело, 2012

5. Романов А.И., Кеворков В.В. Маркетинг и конкурентоспособность медицинской организации. Монография. - М.: Кнорус, 2013.

\section{Информация об авторах}

1. Каприн Андрей Дмитриевич - д. м. н., профессор, чл.-корр РАН, генеральный директор ФГБУ “НМИРЦ» Минздрава России, заведующий кафедрой урологии с курсом онкоурологии РУДН.

2. Костин Андрей Александрович - д. м. н., профессор, первый заместитель генерального директор ФГБУ «НМИРЦ» Минздрава России, заведующий кафедрой урологии, онкологии и радиологии ФПК МР РУДН.

3. Пономаренко Борис Тимофеевич - д. м. н., профессор, кафедра государственной службы и кадровой политики РАНХ и ГС при Президенте Российской Федерации

4. Гриднев Олег Владимирович - к. М. Н., главный врач ГКБ №50

5. Самсонов Юрий Владимирович - к. М. н., ведущий научный сотрудник РЦИТЭО, МНИОИ им. П.А. Герцена - филиал ФГБУ «НМИРЦ» Минздрава России психологического исследования медицинского труда очевидна. Без опоры на системные представления о психологической специфике труда врача и профессиогенеза его личности не могут быть решены задачи повышения профессионализма врача и качества медицинских услуг населению, сочетания профессионально-личностной успешности и удовлетворенности врача своей профессиональной деятельностью. Необходимость повышения социальной значимости медицинского труда - с одной стороны, и отсутствие научно обоснованной системы психологического обеспечения развития врача - с другой, составляют глубинную суть актуальной проблемной ситуации. Этим обусловлена социальная потребность в определении психологической специфики профессиональной деятельности врача. На этой основе может быть сформирована и реализована концепция психологического сопровождения развития и востребования качеств личности врача как профессионала.

\section{References:}

1. Federal'nyi zakon «Ob osnovakh okhrany zdorov'ya grazhdan v Rossiiskoi Federatsii ot 21.11.2011 g. №323-FZ. Punkt 15 st.2. (Russian)

2. Federal'nyi zakon «Ob osnovakh okhrany zdorov'ya grazhdan v Rossiiskoi Federatsii ot 21.11.2011 g. №323-FZ. Punkt 15 st.71. (Russian)

3. Derkach A.A. Sub»ekt: formy, mekhanizmy i puti razvitiya. Kazan': TsIT, 2011. (Russian)

4. Modernizatsiya zdravookhraneniya: novaya situatsiya i novye zadachi. -M.:Delo, 2012. (Russian)

5. Romanov A.I., Kevorkov V.V. Marketing i konkurentosposobnost' meditsinskoi organizatsii. Monografiya. - M.: Knorus, 2013. (Russian)

Information about authors:

1. Kaprin Andrey Dmitrievich - PhD, MD, professor, corresponding member of RAS, director of National Medical Research Radiological Centre of the Ministry of Health of the Russian Federation, head of the Department of urology with the course of oncourology, People's Friendship University of Russia.

2. Kostin Andrey Alexandrovich - PhD, MD, professor, vice director of National Medical Research Radiological Centre of the Ministry of Health of the Russian Federation, head of the Department of urology, oncology and radiology FAT MW, People's Friendship University of Russia.

3. Ponomarenko Boris Timofeevich - doctor of historical Sciences, Professor of the Department of state service and personnel policy, Russian Presidental Academy of National Economy and Public Administration

4. Gridnev Oleg Vladimirovich - PhD, chief doctor of City clinical hospital No. 50

5. Samsonov Yury Vladimirovich - PhD, leading researcher of RCITEO, P. Hertsen MOR

\section{Оформление ссылки для цитирования статьи:}

Каприн А.Д., Костин А.А., Пономаренко Б.Т., Гриднев О.В., Самсонов Ю.В. Психологические аспекты личности врача в процессе его профессионализации. Исследования и практика в медицине. 2015; 2(2): 81-84. DOI:10.17709/2409-2231-2015-2-2-81-84

Kaprin A.D., Kostin A.A., Ponomarenko B.T., Gridnev O.V., Samsonov Y.V. Psychological aspects of the personality of the doctor in the process of professionalization. Issled. prakt. med. 2015; 2(2): 81-84. DOI:10.17709/2409-2231-2015-2-2-81-84

Конфликт интересов. Все авторы сообщают об отсутствии конфликта интересов.

Conflict of interest. All authors report no conflict of interest. 